East African Medical Journal Vol. 86 No. 11 November 2009

ORAL HEALTH KNOWLEDGE, ATTITUDES AND PRACTICES OF PARENTS/GUARDIANS OF PRE-SCHOOL CHILDREN IN MOSHI, TANZANIA

D.S. Rwakatema, DDS, MDS, Lecturer, Department of Dentistry, Kilimanjaro Christian Medical College, Tumaini University, P.O. Box 3010, Moshi, Tanzania and P.M. Ng'ang'a, BDS, MSD, PhD, Associate Professor, Department of Paediatric Dentistry and Orthodontics, Faculty of Dental Sciences, University of Nairobi, P.O. Box 19676-00202, Nairobi, Kenya

Request for reprint to: Dr. D.S. Rwakatema, Department of Dentistry, Kilimanjaro Christian Medical College, Tumaini University, P. O. Box 3010, Moshi, Tanzania

\title{
ORAL HEALTH KNOWLEDGE, ATTITUDES AND PRACTICES OF PARENTS/ GUARDIANS OF PRE-SCHOOL CHILDREN IN MOSHI, TANZANIA
}

\author{
D.S. RWAKATEMA and P.M. NG'ANG'A
}

\begin{abstract}
Objective: To assess the oral health knowledge, attitudes and practices of the parents/ guardians of pre-school children in Moshi, Tanzania.

Design: Cross-sectional study.

Setting: Moshi Municipality, Kilimanjaro region, Tanzania.

Subjects: Parents/guardians of 372 randomly selected 3-5-year-olds.

Results: There were $174(46.8 \%)$ respondents (156 parents and 18 guardians) aged between 20 and 78 years (mean age $35 \pm 2.0$ ). About $76 \%$ of the respondents were in the older age group (over 30 years), $79.9 \%$ were married, $63.2 \%$ had primary education and $79.9 \%$ were either professionals, farmers, skilled technical workers or in business. There were sugar moments reported by the parents/guardians for children with temperaments. Although oral health knowledge was generally poor, more parents/guardians with secondary education showed relatively better dental knowledge than those with primary education ( $\mathrm{p}<0.05)$. More than $75 \%$ of the parents/guardians gave positive responses in regard to maintaining teeth for life for themselves and for their children. A moderate number of respondents $75(43.1 \%)$ reported supervising their children during tooth brushing. However, majority $(92 \%)$ said that their children brushed less than twice a day. Most of the parents/guardians (63.8\%) reported no detrimental habits that can lead to functional traits of malocclusion in their children.

Conclusion: Some parents/guardians practiced sugar moments on their children which were not significantly associated with early childhood caries. The oral hygiene knowledge and practices were inadequate. Most of the respondents were positive about the need to conserve natural teeth for themselves and for their children.
\end{abstract}

\section{INTRODUCTION}

Although the prevalence of dental cariesin Tanzanian pre-school children is still relatively low compared to other countries like South-East Asia (1), there is likely to be a steady increase parallel with the rising economy of the country. According to Tanzanian national oral health policy, preventive oral health approach to the management of oral diseases is the most stressed strategy (2). It has been suggested that early childhood caries (ECC) should be assumed as an infectious disease associated with behavioural and social factors, with public oriented prevention actions being recommended (3). Since parents/ guardians are responsible for almost all health issues related to their children, their role in modeling their children towards practicing preventive oral health through out life is crucial (4) It is therefore expected that preventive oral health behaviour of parents' / guardians' of preschool children would influence their children's behaviour in regard to adapting preventive oral health practices as they grow along. Thus, parents / guardians should be educated about oral health care for their children from inception through the existing setup (5).

Studies donein East Africa in regard to parents' / guardians' knowledge, attitudes and preventive behaviours on oral health of children are scanty (6-9). Some studies in Tanzania $(7,9)$ reported lack of knowledge on prevention in mothers attending reproductive health centres in Tanzania, while another showed relative awareness about feeding factors related to ECC (10). The aim of this study was to assess knowledge, attitudes and practices of parents / guardians relevant to the oral health of their 3-5 year old children in Moshi, Tanzania. 


\section{MATERIALS AND METHODS}

This was a cross sectional study conducted in urban areas of Moshi in 3-5 year-old preschool children and their parents/guardians in 2008. Ethical clearance was sought from Kilimanjaro Christian Medical Centre Ethical Committee. The study was undertaken to evaluate several things. The first part evaluated the morphological and functional traits of malocclusion, ECC and oral hygiene as well as caries risk related to feeding habits of the children. The second part evaluated the parents· / guardians' oral health knowledge, attitudes and practices. Findings for the first part of the study are reported elsewhere $(11,12)$. The present report dwells on the findings of the second part of the study.

A questionnaire probing on socio-demographic characteristics, feeding factors related to ECC; knowledge, attitudes and practices on selected oral health issues; awareness of common oral conditions and habits which may lead to functional traits of malocclusion in children was mailed to each parent / guardian of the 372 children who were examined through the heads of the schools. Details of the sample selection of the children are presented elsewhere (11, 12). The questions used for parents/guardian are presented in Tables 1,2 and 3.

On receiving the completed questionnaires, data were fed in the computer for processing and analysis using Statistical Package for Social Sciences (SPSS) version 12.1 (13) and Epidemiology Information package (Epilnfo) (14). Responses of each question were dichotomized to either present/absent or positive/negative depending on the nature of the oral health domain assessed. There were five oral health domains assessed. These were parents' / guardians' oral health knowledge, actions related to sugar moments on children with temperaments and attitudes on oral health issues, parents/guardians' awareness of oral conditions and habits that may lead to functional traits of malocclusion in their children and oral health practices. In each domain a positive response was given one score and a negative response a zero score.

Chi-square test and Fisher's exact test were used to evaluate for any significant differences between the levels in dichotomous responses for each question and between social demographic characteristics and levels of responses in each oral health domain assessed. A p-value $<0.05$ was considered significant.

\section{RESULTS}

Out of 372 questionnaires mailed, 174(46.8\%) were returned with complete answers. There were $67(38.5 \%)$ male and $107(61.5 \%)$ female respondents. The socio-demographic characteristics of the respondents are presented in Table 4 . In the respective domains respondents above thirty years constituted $76.4 \%$, married $79.9 \%$, those with primary education $63.2 \%$ and those either with professional jobs, farmers, skilled technical works or in business $79.9 \%$.

Table 1

Distribution of parents '/guardians' responses $(n=174)$ on dental knowledge, gingival health as well as oral habits of 3-5 year-old in Moshi, Tanzania

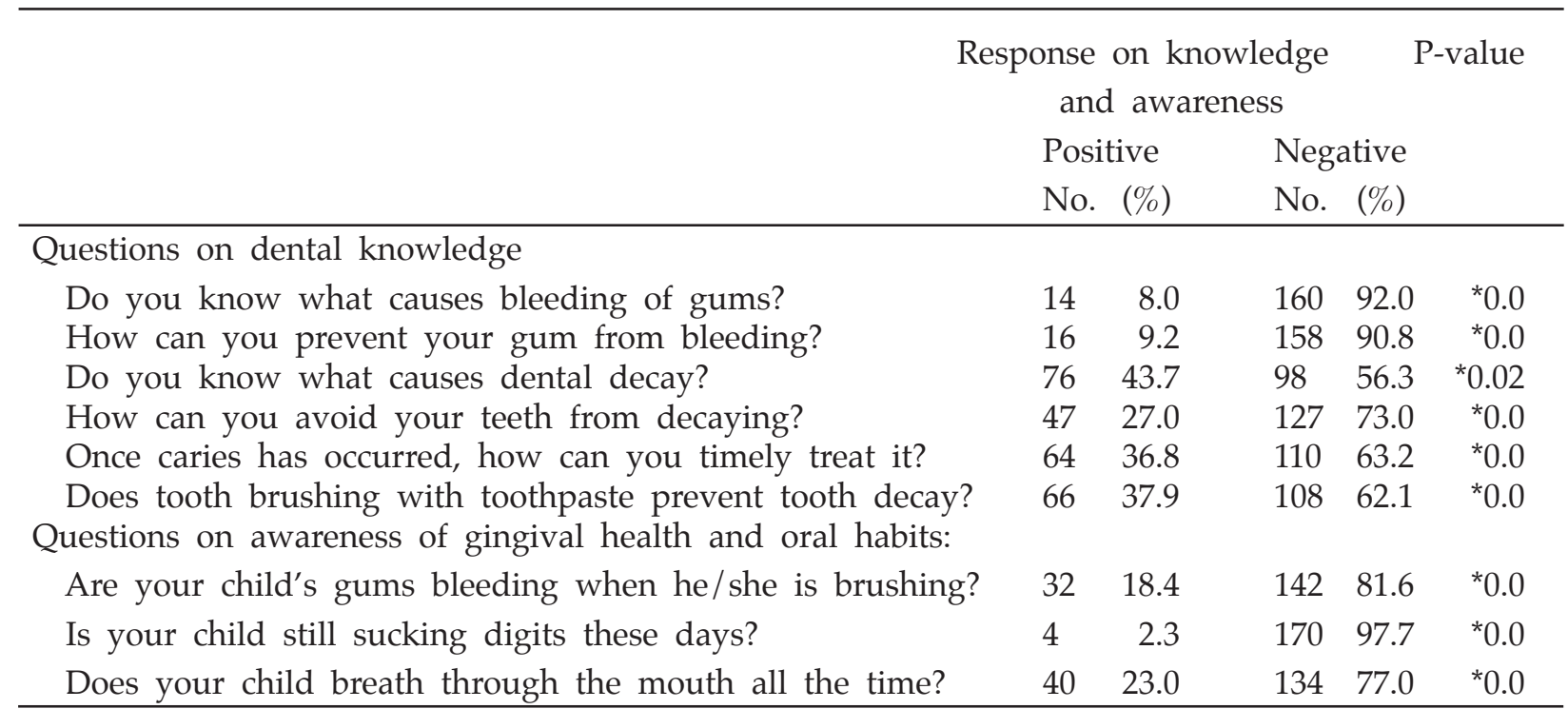

\footnotetext{
* $=\mathrm{p}<0.05$; statistics: Chi-square test
} 
Table 2

Distribution of parents '/guardians' responses $(n=174)$ related to the sugar moments of their children

\begin{tabular}{|c|c|c|c|}
\hline \multirow[t]{3}{*}{ Question } & \multicolumn{2}{|c|}{$\begin{array}{l}\text { Action related to sugar } \\
\text { moment responses }\end{array}$} & \multirow[t]{3}{*}{ P-value } \\
\hline & Positive & Negative & \\
\hline & No. $(\%)$ & No. $(\%)$ & \\
\hline \multicolumn{4}{|l|}{ What did/do you do for your sleepless crying } \\
\hline \multicolumn{4}{|l|}{ baby at night / child who has no obvious reason } \\
\hline $\begin{array}{l}\text { As per your tradition, what are mothers advised } \\
\text { to give or to do to their sleepless, crying baby at }\end{array}$ & & & \\
\hline night (child who has no obvious reason for crying?) & 26.4 & 12873.6 & *0.0 \\
\hline
\end{tabular}

${ }^{*}=\mathrm{p}<0.05$; statistics: Chi-square test

Table 3

Distribution of parents'/guardians' responses $(n=174)$ on the need to conserve natural teeth and preventive oral health practices of their children

\begin{tabular}{|c|c|c|c|c|c|}
\hline & \multicolumn{4}{|c|}{$\begin{array}{l}\text { Response on attitudes } \\
\text { and practices }\end{array}$} & \multirow[t]{3}{*}{ P-value } \\
\hline & Posit & tive & Neg & ative & \\
\hline & No. & $(\%)$ & No. & $(\%)$ & \\
\hline \multicolumn{6}{|l|}{ Questions on attitudes towards natural teeth } \\
\hline $\begin{array}{l}\text { What is your view about having a full denture } \\
\text { instead of your own teeth? }\end{array}$ & 132 & 75.9 & 42 & 24.1 & ${ }^{*} 0.0$ \\
\hline $\begin{array}{l}\text { What is your view about pre-mature loss of all the } \\
\text { deciduous teeth in a child? } \\
\text { Questions on practices }\end{array}$ & 134 & 77 & 40 & 23.0 & *0.0 \\
\hline When was your child's last visit to a dental personnel? & 20 & 11.5 & 154 & 88.5 & ${ }^{*} 0.0$ \\
\hline How often does your child brush teeth? & 14 & 8.0 & 160 & 92.0 & ${ }^{*} 0.0$ \\
\hline Do you supervise your child tooth-brushing? & 75 & 43.1 & 99 & 56.9 & ${ }^{*} 0.01$ \\
\hline
\end{tabular}

Table 4

Distribution of socio-demographic characteristics of parents/guardians $(n=171)$ by levels of their oral health knowledge and caries risk of their children as assessed by sugar moments in Moshi, Tanzania

\begin{tabular}{|c|c|c|c|c|c|c|c|c|c|c|}
\hline \multirow[t]{2}{*}{ Socio-demographic } & \multicolumn{4}{|c|}{$\begin{array}{l}\text { Oral health } \\
\text { knowledge }\end{array}$} & \multicolumn{4}{|c|}{$\begin{array}{l}\text { Sugar moments of } \\
\text { children with } \\
\text { temperament } \\
\text { High Low }\end{array}$} & \multicolumn{2}{|c|}{$\begin{array}{l}\text { Total } \\
\text { number } \\
\text { respondents }\end{array}$} \\
\hline & No. & $(\%)$ & No. & $(\%)$ & No. & $(\%)$ & No. & $(\%)$ & No. & $(\%)$ \\
\hline Younger (20-30 years) & 6 & 14.6 & 35 & 85.4 & 31 & 75.6 & 10 & 24.4 & 41 & 23.6 \\
\hline $\begin{array}{l}\text { Older (over } 30 \text { years) } \\
\text { P-value }\end{array}$ & 13 & $\begin{array}{r}9.8 \\
* 0.4\end{array}$ & 120 & 90.2 & $\begin{array}{l}90 \\
{ }^{*} 0.34\end{array}$ & 67.7 & 43 & 32.3 & 133 & 76.4 \\
\hline Guardian & 1 & 5.6 & 17 & 94.4 & 14 & 77.8 & 4 & 22.2 & 18 & 10.3 \\
\hline Married & 16 & 11.5 & 123 & 88.5 & 95 & 68.3 & 4.4 & 31.7 & 139 & 79.9 \\
\hline Single & 2 & 11.8 & 15 & 882 & 12 & 706 & 5 & 294 & 17 & 98 \\
\hline P-value & & ${ }^{*} 0.74$ & & & ${ }^{*} 0.71$ & & & & & \\
\hline
\end{tabular}




\begin{tabular}{|c|c|c|c|c|c|c|c|c|c|c|}
\hline Primary education & 6 & 5.5 & 104 & 94.5 & 78 & 70.9 & 32 & 29.1 & 110 & 63.2 \\
\hline $\begin{array}{l}\text { Secondary education } \\
\text { P-value }\end{array}$ & 13 & $\begin{array}{l}20.3 \\
{ }^{*} 0.0\end{array}$ & 51 & 79.7 & $\begin{array}{c}43 \\
* 0.61\end{array}$ & 67.2 & 21 & 12.8 & 64 & 36.8 \\
\hline Labourer & 1 & 2.9 & 34 & 97.1 & 24 & 68.6 & 11 & 31.4 & 35 & 20.1 \\
\hline $\begin{array}{l}\text { Professional, farmer } \\
\text { business or skilled work }\end{array}$ & 18 & 12.9 & 121 & 87.1 & 97 & 69.8 & 42 & 30.2 & 139 & 79.9 \\
\hline$P$-value & & *0.13 & & & *0.9 & & & & & \\
\hline
\end{tabular}

Table 5

Distribution of socio-demographic characteristics of parents/guardians $(n=174)$ by levels of their oral health attitudes, awareness of gingival health and oral habits and preventive oral health practices in their 3-5 year-olds in Moshi, Tanzania

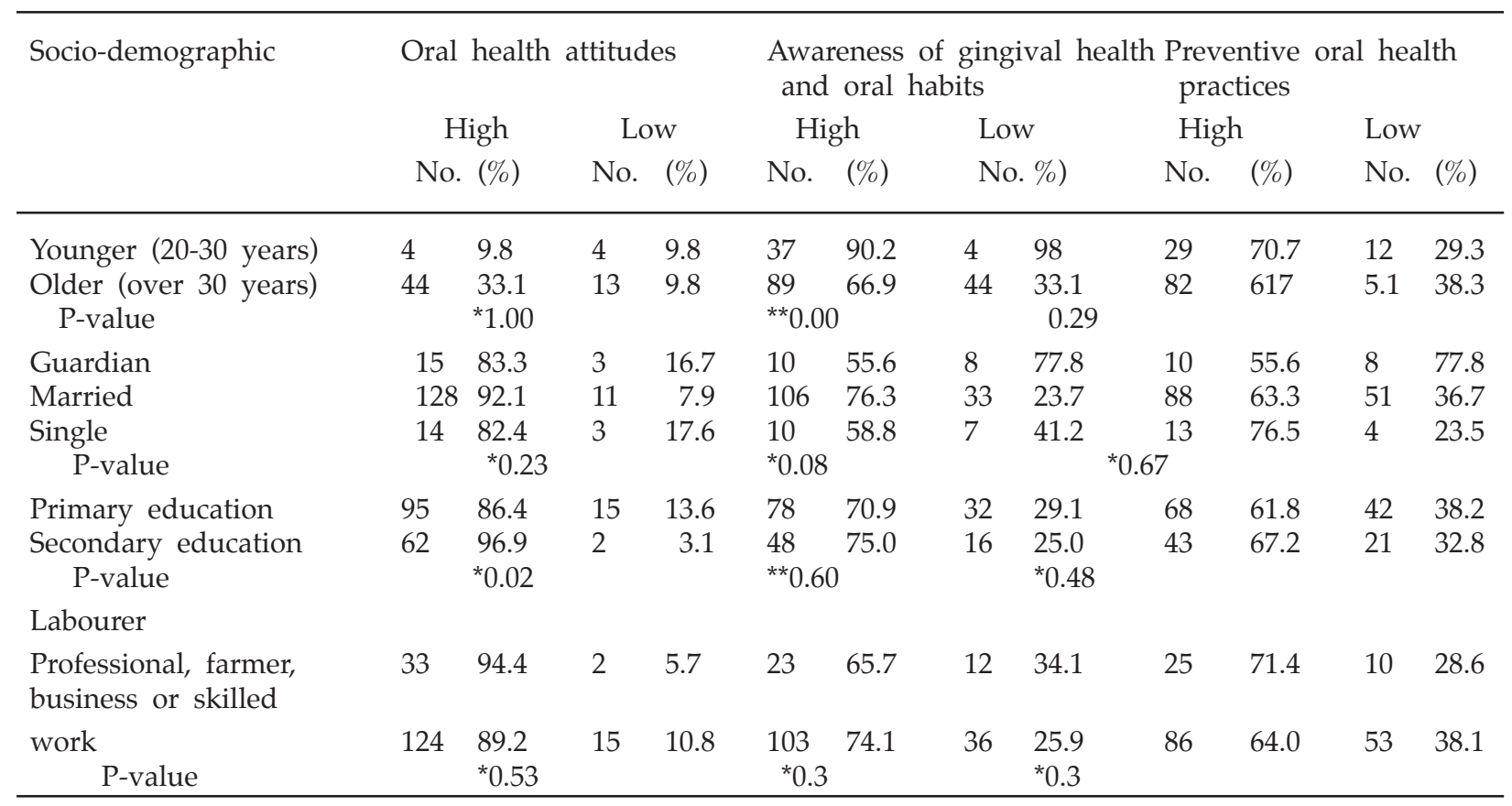

${ }^{* *}=\mathrm{p}<0.05 ;{ }^{*}=\mathrm{p}>0.05$; statistics: Chi-square test

Results for knowledge on oral health and awareness of oral conditions and habits are presented in Table 1. Generally most of the respondents showed poor oral health knowledge. Those with relatively higher education showed significantly better oral health knowledge than those with primary education $(\mathrm{p}<0.05)$ (Table4). Although over $63.8 \%$ of the parents / guardians had no awareness of detrimental oral habits that can lead to functional traits of malocclusion in their children (Table 1), significantly more young parents / guardians had awareness than the old age group $(\mathrm{p}<0.05)$ (Table 5). The data for actions related to sugar moments by the parents / guardians on their children presenting with temperaments are presented in Table 2. Actions related to sugar moments by the parents/guardians were significantly negative $(\mathrm{p}<0.05)$. More than three quarters of the parents / guardians gave positive responses in regard to the preservation of their natural teeth and deciduous teeth of their children (Table 3). Significantly more parents / guardians with secondary schooleducation gave positive responses on conserving teeth than those with primary school education $(\mathrm{p}<0.05)$ (Table 5 ). There were inadequate preventive oral health practices reported by the parents/guardians as shown in Table 3.

\section{DISCUSSION}

A total of $174(46.8 \%)$ parents / guardians out of 372 responded to the questionnaire. Majority of the respondents were female $107(61.5 \%)$. This is not surprising since in this community, mothers are the parents commonly in contact with children in this age group.

In regard to the question on knowledge of the common dental diseases, less than $50 \%$ of parents / guardians responded correctly to the following 
questions: "Do you know what causes dental decay?" (43.7\%), "how can you avoid your teeth from decaying?" (27\%), "once decay has occurred, how can you timely treat it?" $(36.8 \%)$ and "does tooth brushing with toothpaste prevent dental decay?" (36.8\%). This indicated inadequate dental knowledge and therefore a need to educate these parents/guardians. The results showed that those with secondary education scored relatively better on dental knowledge than those with primary education $(\mathrm{p}<0.05)$ (Table 4$)$. It has previously been shown in other communities that correct knowledge of oral health by parents / guardians of preschoolchildren can influence the oral health behaviour of their children (4). Majority of parents / guardians had no awareness of detrimental oral habits in their children that can lead to functional traits of malocclusion (Tables 1). Although the prevalence of functional traits of malocclusion in this population has been reported to be very low (11), parents / guardians need to be made aware of the detrimental oral habits in children that can lead to malocclusion so that they can seek timely intervention for their children.

To probe for psychological and cultural factors that may influence parent's / guardian's role towards oral health in their children, two questions in regard to actions that would betaken by the parents / guardians on a child with temperaments were asked. These were:- "what did/ do you do for your sleepless crying baby at night / child who has no obvious reason for crying?" and "as per your tradition, what are mothers advised to give or to do to their sleepless, crying baby at night / child who has no obvious reason for crying?" (Table 2). Most of the parents/guardians said they would deal with a temperamental baby by leaving the child to cry it out after ruling out genuine reasons of crying. Majority of the parents / guardians did not know of any traditional advices for a night crying baby/child (who has no obvious reason for crying). There were significantly less actions taken by the respondents that would lead to an increase in sugar moments for the two questions asked. When the caries risk levels related to sugar moments were analysed in different groups of socio-demographic characteristics (Table 4), no significant association was found $(p<0.05)$. This indicated that most parents/guardians in this sample did not engage their children in sugar moments that can contribute to the development of ECC.

Toprobefor parents' / guardians' attitude towards maintenance of natural teeth, they were asked to state their view on wearing dentures throughout their life instead of their natural teeth as well as their views on their children having premature loss of their deciduous teeth. Although majority of therespondents gave positive responses for these two questions (Table 3) there were significantly more respondents with primary school education who gave negative responses compared to those with secondary school education $(p<0.05)$ (Table 5). This is in line with studies elsewhere which have shown that oral health knowledge of parents/guardians with secondary education is associated with positive attitudes towards maintaining a healthy dentition (15).

Preventive oral health behaviour was gauged by three questions as shown in Table 3. Majority of the parents / guardians did not practice preventive oral health for their children. This oral health domain was not significantly associated with any of the sociodemographic characteristics $(p>0.05)$ (Table $5)$. These results indicated that there is a very low utilisation of dental services. Only $43.1 \%$ of parents / guardians supervised their children during tooth brushing and the brushing was reported to be less than two times per day by $92 \%$ of the respondents. Below the age of six years, the motor functions of children are not fully developed (16). They therefore need to be supervised during tooth brushing so that assistance can be made where the children are unable to brush properly.

It can be concluded that although most of the parents/guardians in this sample had positive attitude on the need to conserve natural teeth for themselves and for their children, they lacked adequate preventive oral health knowledge. It is therefore important that programmes involving preventive oral health activities in this population be strengthened.

\section{ACKNOWLEDGEMENTS}

This study was supported by Kilimanjaro Christian Medical College of Tumaini University, Tanzania. We are grateful to the authorities of Moshi Municipality, Tanzania, for allowing this study to be undertaken and the children and caretakers of the Moshi Municipal nursery schools visited for their cooperation. The authors appreciate the help of disseminating information by Dr.Sabina Mtweve of the Community Health Department, Kilimanjaro Christian Medical College, Tumaini University during the preparation of this study.

\section{REFERENCES}

1. Milnes, A.R. Description and epidemiology of nursing caries. J. Public Health Dent. 1996; 56: 38-50.

2. Central Oral Health Unit. Policy guidelines for Oral Health Care in Tanzania. $1^{\text {st }}$ edn. Dar es Salaam: Ministry of Health, Tanzania, 2002, pp. 12-31.

3. Weinstein, P. Public health issues in early childhood caries. Comm. Dent. Oral Epidemiol. 1998; 26: 84-90.

4. Shivaprakash, P.K., Elango, J., Baweja, D.K. and Noorani, H.H. The state of infant oral healthcare knowledge and awareness: Disparity among parents and healthcare professionals. J. Indian Soc. Pedod. Prev. Dent. 2009; 27: 39-43. 
5. Sheiham, A. and Watt, R.G. The common risk factor approach: a rational basis for promoting oral health. Comm. Dent. Oral Epidemiol. 2000; 28: 399-406.

6. Nyamu, E.N., Masiga, M.A., Gathece. L.W. and Mutara, L.N. Knowledge attitude and practices of care givers attending the Kenyatta N. Hospital MCH clinics towards oral health of their children. Afr. J. Oral Hlth. Sci. 2003; 4: 326-327.

7. Mziray, H. and Kahabuka, F.K. Prevalence and awareness of early childhood caries among attendees of a reproductive and child health clinic at Mnazi Mmoja dispensary, Dar-es Salaam. Tanz. Dent. J. 2006; 12:35-41.

8. Benedict, P. and Kikwilu, E. Dental caries knowledgeand perceptions among mothers attending reproductive and child health clinics, Kinondoni, Tanzania. Tanz. Dent. J. 2006; 13: 13-17.

9. Mwaiswelo, R.O. and Masalu, J.R. Oral health knowledge and behavior among pregnant women in Kyela District, Mbeya, Tanzania. Tanz. Dent. J. 2007; 14: 47-52.

10. Matee, M., Van 't Hof, M., Masselle, S., et al. Nursing caries, linear hypoplasia and nursing and weaning habits in Tanzanian infants. Comm. Dent. Oral Epidemiol. 1994; 22: 289-293.

11. Rwakatema, D.S. and Ng'ang'a, P.M. Morphological and functional traits of malocclusion in 3-5-year-olds in Moshi, Tanzania. East Afr. Med. J. (in press).

12. Rwakatema, D.S. and Ng'ang'a, P.M. Early childhood caries in Moshi, Tanzania. East Afr. Med. J. 2010 (submitted).

13. SPSS Inc. The Statistical Package for the Social Sciences. Chicago (IL): SPSS, 1997.

14. Centre for Disease Control and Prevention. Epidemiology Information. Atlanta, Georgia, 1998.

15. Williams, N.J., Whittle, J.G. and Gatrell A.C. The relationship between socio-demographic characteristics and dental health knowledge and attitudes of parents with young children. Br. Dent. J. 2002: 193: 651- 654 .

16. Tandon, S. and Radhika, M. Stages of human growth and development (Postnatal). In: S. Tandon (eds.). Textbook of Pedodontics. India: Paras Medical Publisher. 2003, pp 60-74. 